\title{
EFEITO dA APLICAÇÃo de PELÍCULA de FÉCULA de MANDIOCA NA CONSERVAÇÃO PÓS-COLHEITA DE TOMATE ${ }^{1}$
}

\author{
Simone DAMASCENO ${ }^{2, *}$, Patrícia Vieira Sutil de OLIVEIRA², Edemar MORO², \\ Eurides Küster MACEDO JR², Mário César LOPES², Nívea Maria VICENTINI ${ }^{3}$
}

\begin{abstract}
RESUMO
O presente trabalho teve por objetivo avaliar a qualidade e a vida útil pós-colheita de frutos de Tomate (Lycopersicon esculentum Mill) utilizando recobrimento com película de fécula de mandioca. Após a seleção os frutos foram mergulhados em suspensões a 2 e $3 \%$ de fécula de mandioca, secos ao ar e armazenados em condição ambiente, onde a temperatura e a umidade relativa do período variaram de 16 a $21^{\circ} \mathrm{C}$ e 51 a $91 \%$, respectivamente. O experimento foi constituído de dois lotes de frutos, sendo o primeiro o grupo não-destrutivo (avaliação de perda de massa). O segundo lote de frutos, constituiu o grupo destrutivo no qual analisou-se textura, pH e sólidos solúveis totais. Os frutos foram avaliados aos $0,4,8,11,14,18$ e 22 dias. O delineamento experimental foi inteiramente casualizado, com cinco repetições para o primeiro grupo e três repetições para o grupo destrutivo. Os dados experimentais obtidos foram submetidos à analise de variância e as médias comparadas através do teste de Tukey ao nivel de $5 \%$ de probabilidade. Os tratamentos não influenciaram significativamente a perda de massa e a textura. Entretanto, os frutos recobertos com película a $3 \%$ apresentaram melhor aparência do que os frutos testemunha e com película a $2 \%$. O efeito das películas portanto, não foi prejudicial, apenas estético.

Palavras-chave: tomate; filmes de fécula de mandioca; pós-colheita.
\end{abstract}

\section{SUMMARY}

APLICATION OF CASSAVA STARCH FILM EFFECT IN THE TOMATO POSTHARVEST CONSERVATION. This work was made to evaluate the fruit properties and postharvest life of tomato (Lycopersicon esculentum Mill) coated with cassava starch film. After the selection the fruits were dipped in 2 and $3 \%$ starch suspensions, dried naturally and stored in room conditions. The average temperature and relative humidity for the period varied respectively among $16-21^{\circ} \mathrm{C}$ and $51-91 \%$. The experiment was compound of a no-destructive group (evaluation of weight loss). Another group was the destructive group (evaluation of $\mathrm{pH}$, texture and total soluble solids). Samples of the three groups were taken in $0,4,8,11,14,18$ and 22 days. The experiment was carried out in a completely randomized statistical design, with 5 replications for the control group and 3 replications for the destructive group. It was founded that the treatments didn't influence significantly the weight loss and the texture. However the fruits coated with $3 \%$ starch suspension presented better aspect at the end of the experiment than control and of the fruits immersed in the $2 \%$. The coate effect on tomato fruits was not harzard, only esthetic.

Keywords: tomato; cassava starch film; postharvest.

\section{1 - INTRODUÇÃO}

O tomate apresenta-se entre as hortaliças mais comercializadas no mundo. Os principais países produtores são Estados Unidos, Itália, Turquia, Egito, Espanha, Portugal, Rússia e Brasil [1]. O tomate é considerado um produto altamente perecivel após a colheita, pela fragilidade dos seus tecidos e pela manutenção de sua atividade metabólica, demandando inúmeros esforços na sua conservação pós-colheita. Sendo um fruto climatério, o seu amadurecimento inicia-se com a elevação da atividade respiratória, acarretando uma série de transformações em suas características físicas e químicas, dentre elas perda da clorofila, sintese de carotenóides e amolecimento [16].

Para diminuição das perdas pós-colheita são utilizadas algumas técnicas, entre as quais está a aplicação de ceras [6].

No uso de ceras como superficie protetora em frutos e hortaliças, alguns cuidados devem ser tomados com relação à espessura da camada a ser aplicada. Quando

\footnotetext{
Recebido para publicação em 29/11/2001. Aceito para publicação em 24/01/2003 (000782).

${ }^{2}$ Depto. de Tecnologia de Produtos Agropecuários - Curso de Engenharia Agricola da UNIOESTE. Rua Universitária 2069 Caixa Postal 711 CEP: 85819110 - Cascavel-PR. Fone: (45)220-3155, Fax: (45) 324-4566. E-mail: simoned@unioeste.br. Agronomia/UNIOESTE/Marechal Cândido Rondon-PR ${ }^{3}$ CERAT/FCA/UNESP - Botucatu-SP.

* A quem a correspondência deve ser enviada.
}

muito fina, não apresenta efeito quanto à perda de umidade; quando em quantidade excessiva, pode provocar o desenvolvimento de sabores estranhos [6].

No entanto, apesar de se mostrar eficiente, a aplicação de ceras tem como principal limitação seu custo e o possivel efeito residual nos frutos [12]. Como alternativa para esses problemas, CEREDA et al. [5] citam a possibilidade de recobrir matérias-primas com fécula de mandioca gelatinizada que, devido as suas propriedades quando desidratadas, podem formar peliculas semelhantes às de celulose em resistência e transparência, representando uma alternativa potencial a ser usada na conservação de frutas e hortaliças.

Além do uso de fécula de mandioca na elaboração de filmes para recobrimento de frutas e hortaliças pode-se citar a possibilidade de seu uso na elaboração de bandejas biodegradáveis para acondicionamento de produtos, tal como avaliado por CASTRO \& CEREDA [3] que testaram a conservação de tomate em bandeja de fécula de mandioca envolvida com filme de cloreto de polivinila.

Nesta linha de recobrimento de vegetais com película de fécula de mandioca vêm sendo desenvolvidos teses e artigos avaliando a conservação de inúmeros produtos, tais como goiaba [10], mamão "papaya" [4], laranja [14], tomate [15], pepino [11], limão [7], couve-flor [12] e pimentão [13].

Sendo o uso de película de fécula de mandioca uma alternativa recente de conservação pós-colheita de pro- 
dutos agricolas, justifica-se o desenvolvimento de pesquisas que visem avaliar seu efeito em outros produtos. Neste contexto, o presente trabalho teve por objetivo avaliar o efeito do recobrimento com película de fécula de mandioca na conservação pós-colheita de frutos de tomate.

\section{2 - MATERIAL E MÉTODOS}

Os frutos foram obtidos no comércio local de Marechal Cândido Rondon (PR), selecionados quanto à uniformidade (tamanho e coloração) e transportados para o Laboratório de Tecnologia de Alimentos da UNIOESTE, Campus de M. C. Rondon. A película foi preparada a partir da suspensão de fécula de mandioca comercial em água, para recobrimento pós-colheita. Após a lavagem e desinfecção em solução clorada contendo $100 \mathrm{mg} / \mathrm{L}$ de cloro ativo [9], os frutos foram divididos em 3 lotes, sendo efetuado o recobrimento com fécula de mandioca ( 2 e $3 \%$ ) em 2 deles, constituindo-se o outro na testemunha (0\%). Para obter as concentrações de 2 e $3 \%$ suspendeu-se, respectivamente, 20 e $30 \mathrm{~g}$ de fécula de mandioca em 1 litro de água destilada, sendo as suspensões aquecidas a $70^{\circ} \mathrm{C}$ e resfriadas a temperatura ambiente, para a imersão dos frutos [10]. O armazenamento ocorreu em condições ambiente, com temperatura e umidade relativa que variaram de 16 a $21^{\circ} \mathrm{C}$ e 51 a $91 \%$, respectivamente. O experimento foi composto de lotes de frutos, compreendendo o grupo controle (avaliação de fatores não destrutivos), no qual foi avaliado a perda de massa. O segundo lote de frutos, constituiu o grupo destrutivo no qual analisou-se a textura, o $\mathrm{pH}$ e os sólidos solúveis totais [10]. As avaliações foram realizadas aos $0,4,8$, $11,14,18$ e 22 dias de armazenamento. O delineamento experimental foi inteiramente casualisado, com cinco repetições para o grupo controle e três repetições para o grupo destrutivo. Os dados experimentais obtidos foram submetidos à analise de variância e as médias comparadas através do teste de Tukey ao nivel de $5 \%$ de probabilidade. A perda de massa ao longo do experimento foi expressa em porcentagem, calculada sobre o peso inicial. A textura foi medida nas laterais dos frutos, utilizando-se penetrômetro Fruit Pressure tester mod. FT 327, sendo os resultados expressos em quilograma. O teor de sólidos solúveis totais foi determinado em refratômetro de bancada e o resultado expresso em ${ }^{\circ} \mathrm{Brix}$ [2]. $\mathrm{O} \mathrm{pH}$ foi determinado no extrato aquoso, em potenciômetro "Digimed DMPH-2" [8]. O experimento foi conduzido até o 22 ㅇ dia de armazenamento.

\section{3 - RESULTADOS E DISCUSSÃo}

\section{1 - Perda de massa:}

Os resultados relativos à análise de variância da perda de massa de frutos de tomate, após a colheita e durante o periodo de armazenamento testado, estão apresentados na Tabela 1.

Pode-se observar através da análise de variância para a perda de massa dos frutos de tomate, que houve dife- rença significativa ao nivel de $5 \%$ de probabilidade, para a película utilizada e período de armazenamento, mas que não ocorreu interação significativa entre a película e o tempo (Tabela 1).

TABELA 1. Análise de variância (perda de massa)

\begin{tabular}{lrrc}
\hline Causa de variação & GL & QM & Prob > F \\
\hline Película & 2 & 2,76 & $0,00645^{*}$ \\
Tempo & 6 & 64,71 & $0,00001^{*}$ \\
Película X Tempo & 12 & 0,18 & $0,97827 \mathrm{~ns}$ \\
Erro & 84 & 0,51 & \\
Total & 104 & & \\
\hline
\end{tabular}

* significativo ao nivel de $5 \%$ pelo teste Tukey

$\mathrm{Na}$ Tabela 2 são apresentados os resultados do teste de comparação múltipla de médias através do teste de Tukey para película.

TABELA 2. Perda de massa em frutos de tomate recobertos com película de fécula de mandioca

$\begin{array}{cc}\text { Nível de recobrimento } & \text { Perda de massa (\%) } \\ 0 \% & 3,10 \mathrm{ab} \\ 2 \% & 3,46 \mathrm{a} \\ 3 \% & 2,90 \mathrm{~b}\end{array}$

*médias seguidas de mesma letra não diferem entre si significativamente ao nível de 5\% de probabilidade pelo teste de Tukey DMS: 0,40785

Observou-se que o recobrimento dos frutos de tomate com película de fécula de mandioca (2 e 3\%) não apresentou diferença significativa da testemunha para o parâmetro perda de massa, embora o tratamento com $3 \%$ de fécula tenha apresentado menores perdas de massa ao longo do armazenamento. Tal comportamento também foi observado por outros autores [3, 10, 11, 12].

Quanto ao período de armazenamento pós-colheita, observou-se que ocorreu diminuição na massa dos frutos de tomate ao longo do armazenamento (Figura 1).

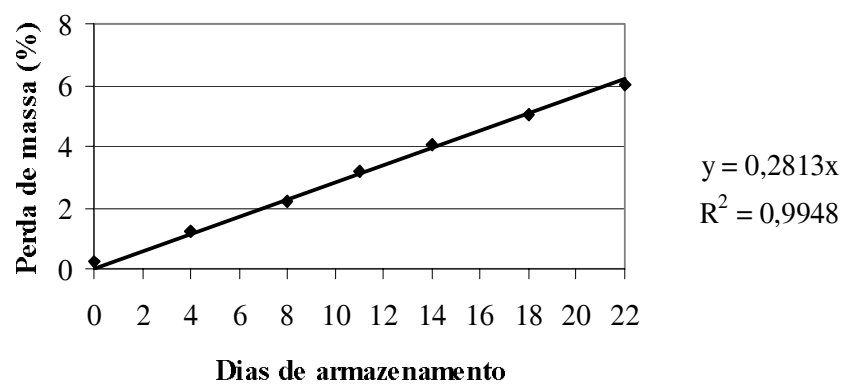

FIGURA 1. Perda de massa de frutos de tomate durante o armazenamento

\section{$3.2-\mathrm{pH}$}

Os resultados relativos à análise de variância do $\mathrm{pH}$ dos frutos de tomate, após a colheita e durante o período de armazenamento, estão apresentados na Tabela 3.

Pode-se observar que para o $\mathrm{pH}$ dos frutos de tomate, houve diferença significativa ao nivel estabelecido, 
para a pelicula utilizada e periodo de armazenamento; não demonstrando interação significativa entre a pelicula e o armazenamento (Tabela 3).

TABELA 3. Análise de variância (pH, textura, sólidos solúveis totais).

\begin{tabular}{l|r|c|c|c}
\hline Causa de variação & \multirow{2}{*}{ GL } & \multicolumn{3}{|c}{ QM } \\
\cline { 3 - 5 } & & $\mathrm{pH}$ & Textura & SST \\
\hline Película & 2 & $0,203^{*}$ & $2,440^{*}$ & $1,830^{*}$ \\
Tempo & 6 & $0,084^{*}$ & $1,931^{*}$ & $1,035^{*}$ \\
Película X Tempo & 12 & $0,017 \mathrm{~ns}$ & $0,935 \mathrm{~ns}$ & $0,240 \mathrm{~ns}$ \\
Erro & 42 & 0,014 & 0,702 & 0,241 \\
Total & 62 & & & \\
\hline
\end{tabular}

* significativo ao nivel de $5 \%$

Nas Tabelas 4 e 5 são apresentados os resultados do teste de comparação múltipla de médias através do teste de Tukey, para película e periodo de armazenamento, respectivamente, para o $\mathrm{pH}$ dos frutos de tomate.

TABELA 4. Valores de $\mathrm{pH}$ em frutos de tomate com película de fécula de mandioca

\begin{tabular}{cc}
\hline Nível de recobrimento & $\mathrm{pH}$ \\
\hline $0 \%$ & $3,97 \mathrm{~b}$ \\
$2 \%$ & $4,17 \mathrm{a}$ \\
$3 \%$ & $4,05 \mathrm{~b}$ \\
\hline
\end{tabular}

*médias seguidas de mesma letra não diferem entre si significativamente ao nivel de $5 \%$ de probabilidade pelo teste de Tukey

DMS: 0,08385

TABELA 5. Valores de $\mathrm{pH}$ em frutos de tomate ao longo do armazenamento

\begin{tabular}{cl}
\hline Dias de armazenamento & $\mathrm{pH}$ \\
\hline 0 & $3,94 \mathrm{c}$ \\
4 & $3,98 \mathrm{c}$ \\
8 & $4,01 \mathrm{bc}$ \\
11 & $4,06 \mathrm{abc}$ \\
14 & $4,09 \mathrm{abc}$ \\
18 & $4,20 \mathrm{a}$ \\
22 & $4,18 \mathrm{ab}$ \\
\hline
\end{tabular}

*médias seguidas de mesma letra não diferem entre si significativamente ao nivel de $5 \%$ de probabilidade pelo teste de Tukey

O tratamento que recebeu película de fécula de mandioca a $2 \%$ apresentou média de $\mathrm{pH}$ dos frutos de tomate superior aos demais tratamentos, os quais não apresentaram diferença significativa entre as médias de $\mathrm{pH}$ (Tabela 4). Em experimento com frutos de goiaba e couve-flor recobertos com película de fécula de mandioca, [10, 12], respectivamente, não observaram diferenças significativas entre os tratamentos que receberam ou não o recobrimento.

Durante o período de armazenamento dos frutos de tomate, observou-se uma tendência de aumento do $\mathrm{pH}$ ao longo do amadurecimento e início da senescência ( $\mathrm{Ta}$ bela 5), também observado por OLIVEIRA [10] com goiaba recoberta com película de fécula de mandioca.

\section{3 - Textura}

Os resultados relativos à análise de variância da textura dos frutos de tomate, após a colheita e durante o período de armazenamento, estão apresentados na $\mathrm{Ta}$ - bela 3. Observa-se que para a textura dos frutos de tomate, houve diferença significativa ao nivel estabelecido, para a película utilizada e período de armazenamento, mas não ocorreu interação significativa entre a película e o armazenamento (Tabela 3).

Nas Tabelas 6 e 7 são apresentados os resultados do teste de comparação múltipla de médias através do teste de Tukey para textura em função da concentração de fécula de mandioca na película e periodo de armazenamento.

TABELA 6. Textura em frutos de tomate com película de fécula de mandioca.

\begin{tabular}{cc}
\hline Nível de recobrimento & Textura $(\mathrm{Kg})$ \\
\hline $0 \%$ & $3,58 \mathrm{ab}$ \\
$2 \%$ & $3,41 \mathrm{~b}$ \\
$3 \%$ & $4,06 \mathrm{a}$ \\
\hline
\end{tabular}

*médias seguidas de mesma letra não diferem entre si significativamente ao nivel de 5\% de probabilidade pelo teste de Tukey; DMS: 0,62835

TABELA 7. Textura em frutos de tomate ao longo do armazenamento

$\begin{array}{cc}\text { Dias de armazenamento } & \text { Textura }(\mathrm{Kg}) \\ 0 & 4,37 \mathrm{a} \\ 4 & 3,57 \mathrm{ab} \\ 8 & 3,82 \mathrm{ab} \\ 11 & 3,42 \mathrm{ab} \\ 14 & 4,13 \mathrm{ab} \\ 18 & 3,49 \mathrm{ab} \\ 22 & 2,99 \mathrm{~b}\end{array}$

"médias seguidas de mesma letra não diferem entre si significativamente ao nivel de $5 \%$ de probabilidade pelo teste de Tukey

Os tratamentos que receberam película de fécula de mandioca a $2 \%$ e $3 \%$ não diferiram estatisticamente da testemunha (Tabela 6). Para este parâmetro observouse que mesmo não havendo diferenças, os frutos recobertos com película a 3\% apresentaram melhor aparência que os da testemunha e película a $2 \%$, devido à textura mais firme. No entanto esta diferença visual na textura não foi apreendida pela sensibilidade do equipamento.

Tal resultado está de acordo com experimentos envolvendo limão siciliano [7] e pimentão [13] que também apresentaram melhoria na textura quando recobertos com película de fécula de mandioca a $3 \%$.

Ao longo do armazenamento observou-se decréscimo nos valores de textura em decorrência, provavelmente, da solubilização de substâncias pécticas [6] (Tabela 7).

\section{4 - Sólidos solúveis totais (SST)}

Os resultados relativos à análise de variância dos sólidos solúveis totais dos frutos de tomate, após a colheita e durante o periodo de armazenamento, estão apresentados na Tabela 3. Pode-se observar que para os sólidos solúveis totais dos frutos de tomate, houve diferença significativa ao nivel de 5\% de significância, para a película utilizada e período de armazenamento. Não houve interação significativa entre a película e o tempo de armazenamento (Tabela 3). 
Nas Tabelas 8 e 9 são apresentados os resultados do teste de comparação múltipla de médias, através do teste de Tukey para sólidos solúveis totais, em função da concentração de fécula de mandioca na película e período de armazenamento, respectivamente.

TABELA 8. Sólidos solúveis totais em frutos de tomate com película de fécula de mandioca

$\begin{array}{cc}\text { Nível de recobrimento } & \text { Sólidos solúveis totais (\%) } \\ 0 \% & 4,45 \mathrm{a} \\ 2 \% & 3,88 \mathrm{~b} \\ 3 \% & 4,03 \mathrm{~b}\end{array}$

*médias seguidas de mesma letra não diferem entre si significativamente ao nivel de $5 \%$ de probabilidade pelo teste de Tukey DMS: 0,36817

TABELA 9. Sólidos solúveis totais em frutos de tomate ao longo do armazenamento

$\begin{array}{cc}\text { Dias de armazenamento } & \text { Sólidos solúveis totais }(\%) \\ 0 & 4,69 \mathrm{a} \\ 4 & 4,20 \mathrm{ab} \\ 8 & 3,98 \mathrm{ab} \\ 11 & 4,23 \mathrm{ab} \\ 14 & 4,28 \mathrm{ab} \\ 18 & 3,64 \mathrm{~b} \\ 22 & 3,84 \mathrm{~b}\end{array}$

*médias seguidas de mesma letra não diferem entre si significativamente ao nivel de $5 \%$ de probabilidade pelo teste de Tukey

Os tratamentos com película de fécula de mandioca a 2 e 3\% diferiram estatisticamente da testemunha, apresentando teores mais baixos de SST (Tabela 8).

Durante o armazenamento observou-se diminuição no teor de sólidos solúveis totais (Tabela 9), o que foi observado também por VIEITES et al. [14] e HENRIQUE [7] em trabalho com aplicação de película de fécula de mandioca em laranja e limão, respectivamente.

\section{4 - CONCLUSÕES}

Nas condições do ensaio a maturação dos frutos de tomate prosseguiu normalmente. A utilização de película de fécula de mandioca no recobrimento dos frutos não melhorou a conservação pós-colheita, mas também não foi prejudicial. A película não reduziu significativamente a perda de massa dos frutos, embora para a concentração a 3\% a perda de massa tenha sido menor que a apresentada pela testemunha e película a $2 \%$. A aplicação de película de fécula de mandioca na concentração mais elevada (3\%), trouxe ao fruto de tomate um aspecto melhor de conservação, tornando o produto mais atraente.

\section{5 - REFERÊNCIAS BIBLIOGRÁFICAS}

[1] AGRIANUAL. Anuário da Agricultura Brasileira. São Paulo: FNP Consultoria e Comércio, 1997. 402-408p.
[2] ASSOCIATION OF OFFICIAL ANALYTICAL CHEMISTRY. Official methods as analysis of the association of official analytical chemistry. 11 ed. Washington, 1970. $1015 \mathrm{p}$.

[3] CASTRO, T. M. R.; CEREDA, M. P. Confecção e utilização de embalagens rígidas biodegradáveis, desenvolvida a partir de fécula de mandioca. III Simpósio Latino Americano de Ciências de Alimentos, Campinas, SP, 1999.

[4] CEREDA, M. P. ; BERTOlini, A. C.; Evangelista, R. M. Uso do amido em substituição às ceras na elaboração de películas na conservação pós-colheita de frutas e hortaliças: estabelecimento de curvas de secagem.. $\mathbf{7}^{\circ}$ Congresso Brasileiro de Mandioca, Recife, PE, 1992.

[5] CEREDA, M. P. ; BERTOLINI, A. C.; SILVA, A. P. ; OLIVEIRA, M. A.; EVANGELISTA, R. M. Peliculas de almidón para la preservación de frutas. Congresso de Polimeros Biodegradables: Avances y Perspectivas, Buenos Aires, Argentina, 1995.

[6] CHITARRA, M. I. F; CHITARRA, A. B. Pós-colheita de frutos e hortaliças: Fisiologia e manuseio. Lavras: ESAL/ FAEPE, 1990.

[7] HENRIQUE, C. M. Película de Fécula de Mandioca na Conservação pós-colheita de limão siciliano desverdecido. Botucatu/SP, 1999. 165 p. Dissertação de Mestrado Faculdade de Ciências Agronômicas, Universidade Estadual Paulista (UNESP).

[8] INSTITUTO ADOLFO LUTZ. Normas analíticas: métodos químicos e físico-químicos para análise de alimentos. $2^{\mathrm{a}}$ ed., São Paulo, 1977. 1:371p.

[9] MEDINA, P. V. L. Manejo pós-colheita de pimentões e pimentas. Informe Agropecuário, v. 10, n. 113, p. 72-76, 1984.

[10] OLIVEIRA, M. A. Utilização de Película de Fécula de Mandioca como alternativa à Cera Comercial na conservação pós-colheita de frutos de Goiaba. Piracicaba/SP. 1996. 73 p. Dissertação de Mestrado - Escola Superior de Agricultura Luiz de Queiroz, Universidade de São Paulo (USP).

[11] VICENTINI, N. M.; CEREDA M. P. Uso de filmes de fécula de mandioca em conservação pós-colheita de pepino (Cucumis sativus L.). Brazilian Journal of Food Tecnhnology. v. 2, n. 1-2, p. 87-90, 1999.

[12] VICENTINI, N. M. Utilização de Películas de fécula de mandioca para a conservação pós-colheita de couve-flor. Botucatu/SP, 1999. 55p. Dissertação de Mestrado Faculdade de Ciências Agronômicas, Universidade Estadual Paulista (UNESP).

[13] VICENTINI, N. M.; CASTRO T. M. R. de; CEREDA M. P. Influência de películas de fécula de mandioca na qualidade pós-colheita de frutos de pimentão. Ciênc. Tecnol. Aliment. v. 19, n. 1, p. 127-130, 1999.

[14] VIEITES, R. L.; ARRUDA, M. C..; GODOY, L. J. G. Utilização de cera e película de fécula no armazenamento de laranja pera sob refrigeração. Semina: Ci. Agr., v. 17, n. 1 , p. 83-87, 1996a.

[15] VIEITES, R. L.; DAIUTO, A. R.; BONASSI, I. A. Efeito da utilização de cera e películas de amido e fécula em condições de refrigeração na conservação de tomate. $\mathbf{1 5}^{\circ}$ Congresso Brasileiro de Ciência e Tecnologia de Alimentos, Poços de Caldas, MG, 1996b.

[16] VIEITES, R. L. 1998. Conservação pós-colheita de tomate (Lycopersicon esculentum Mill). Botucatu: Fepaf. 